\title{
EAU Guidelines on Renal Cell Carcinoma: 2014 Update
}

\author{
Borje Ljungberg $^{a}$, Karim Bensalah ${ }^{b}$, Steven Canfield ${ }^{c}$, Saeed Dabestani ${ }^{d}$, Fabian Hofmann $^{e}$, \\ Milan Hora ${ }^{f}$, Markus A. Kuczyk ${ }^{g}$, Thomas Lam ${ }^{h}$, Lorenzo Marconi ${ }^{i}$, Axel S. Merseburger ${ }^{g}$, \\ Peter Mulders $^{j}$, Thomas Powles $^{k}$, Michael Staehler $^{l}$, Alessandro Volpe ${ }^{m}$, Axel Bex $^{n, *}$ \\ ${ }^{a}$ Department of Surgical and Perioperative Sciences, Urology and Andrology, Umeå University, Umeå, Sweden; ${ }^{\mathrm{b}}$ Department of Urology, University of \\ Rennes, Rennes, France; ${ }^{\mathrm{c}}$ Division of Urology, University of Texas Medical School at Houston, Houston, TX, USA; ${ }^{\mathrm{d}}$ Department of Urology, Skåne University \\ Hospital, Malmö, Sweden; ${ }^{\mathrm{e}}$ Department of Urology, Sunderby Hospital, Sunderby, Sweden; ${ }^{\mathrm{f}}$ Department of Urology, Faculty Hospital and Faculty of \\ Medicine in Pilsen, Charles University, Prague, Czech Republic; ${ }^{\mathrm{g}}$ Department of Urology and Urologic Oncology, Hanover University Medical School, \\ Hanover, Germany; ${ }^{\mathrm{h}}$ Academic Urology Unit, University of Aberdeen, Aberdeen, UK; ${ }^{\mathrm{i}}$ Department of Urology, Coimbra University Hospital, Coimbra, \\ Portugal; ${ }^{\mathrm{j}}$ Department of Urology, Radboud University, Nijmegen, The Netherlands; ${ }^{\mathrm{k}}$ Barts Cancer Institute, Queen Mary University of London, \\ St. Bartholomew's Hospital, London, UK; ${ }^{1}$ Urologische Klinik, Klinikum der Ludwig-Maximilians Universität, Munich, Germany; ${ }^{\mathrm{m}}$ Division of Urology, \\ Maggiore della Carità Hospital, University of Eastern Piedmont, Novara, Italy; ${ }^{\mathrm{n}}$ Department of Urology, The Netherlands Cancer Institute, Antoni van \\ Leeuwenhoek Hospital, Amsterdam, The Netherlands
}

\section{Article info}

Article history:

Accepted January 2, 2015

Keywords:

Guideline

Systematic review

Meta-analysis

Renal cell carcinoma

\begin{abstract}
Context: The European Association of Urology Guideline Panel for Renal Cell Carcinoma (RCC) has prepared evidence-based guidelines and recommendations for RCC management.

Objectives: To provide an update of the 2010 RCC guideline based on a standardised methodology that is robust, transparent, reproducible, and reliable.

Evidence acquisition: For the 2014 update, the panel prioritised the following topics: percutaneous biopsy of renal masses, treatment of localised RCC (including surgical and nonsurgical management), lymph node dissection, management of venous thrombus, systemic therapy, and local treatment of metastases, for which evidence synthesis was undertaken based on systematic reviews adhering to Preferred Reporting Items for Systematic Reviews and Meta-analyses (PRISMA) guidelines. Relevant databases (Medline, Cochrane Library, trial registries, conference proceedings) were searched (January 2000 to November 2013) including randomised controlled trials (RCTs) and retrospective or controlled studies with a comparator arm. Risk of bias (RoB) assessment and qualitative and quantitative synthesis of the evidence were performed. The remaining sections of the document were updated following a structured literature assessment. Evidence synthesis: All chapters of the RCC guideline were updated. For the various systematic reviews, the search identified a total of 10862 articles. A total of 151 studies reporting on 78792 patients were eligible for inclusion; where applicable, data from RCTs were included and meta-analyses were performed. For RCTs, there was low RoB across studies; however, clinical and methodological heterogeneity prevented data pooling for most studies. The majority of studies included were retrospective with matched or unmatched cohorts based on single or multi-institutional data or national registries. The exception was for systemic treatment of metastatic RCC, in which several RCTs have been performed, resulting in recommendations based on higher levels of evidence.
\end{abstract}

\footnotetext{
* Corresponding author. Division of Surgical Oncology, Department of Urology, The Netherlands Cancer Institute, Plesmanlaan 121, 1066 CX Amsterdam, The Netherlands. Tel. +31 205122553 Fax: +31205122554.

E-mail address: a.bex@nki.nl (A. Bex).
}

http://dx.doi.org/10.1016/j.eururo.2015.01.005

0302-2838/C 2015 European Association of Urology. Published by Elsevier B.V. All rights reserved. 
Conclusions: The 2014 guideline has been updated by a multidisciplinary panel using the highest methodological standards, and provides the best and most reliable contemporary evidence base for RCC management.

Patient summary: The European Association of Urology Guideline Panel for Renal Cell Carcinoma has thoroughly evaluated available research data on kidney cancer to establish international standards for the care of kidney cancer patients.

(C) 2015 European Association of Urology. Published by Elsevier B.V. All rights reserved.

\section{Introduction}

The European Association of Urology (EAU) Renal Cell Carcinoma (RCC) Guideline Panel has compiled these clinical guidelines to provide clinicians with evidencebased information and recommendations for the management of patients with RCC. The RCC panel is an international group consisting of clinicians with particular expertise in this field. To meet the requirements for a multidisciplinary approach, the panel has recently been reinforced by several experts, including a medical oncologist, pathologists, radiologists, a methodologist, biostatisticians, and members of patient advocacy groups. The EAU RCC guidelines were first published in 2000 [1], with a subsequent full update in 2006 and partial updates in 2007, 2008, 2009, 2010 [2], and 2013. The current 2014 document presents a full-text update and is fundamentally different from the versions published previously. The panel adopted Cochrane methodology and Preferred Reporting Items for Systematic Reviews and Meta-analyses (PRISMA) guidelines [3] in undertaking systematic reviews (SRs) in 2011 to ensure that the evidence synthesis was performed in a robust, standardised, transparent, and reproducible manner. For the 2014 update, the panel has proceeded with the SR work in a stepwise fashion. The majority of sections have been updated based on SRs; however, a few sections of the document have been updated following a structured literature assessment, as shown in Table 1. As a result, the previous guideline has been completely revised and supplemented with a section on management of venous tumour thrombus. A detailed version of the current guideline including full references, level of evidence, and grade of recommendations is available at www.uroweb.org [4]. The focus for the next $2 \mathrm{yr}$ is for the complete guidelines document to be based on SRs for evidence synthesis, as SRs represent the highest possible level of data work-up.

\section{Evidence acquisition}

All chapters of the 2014 RCC Guidelines publication have been updated. As mentioned in Table 1, the consistency of the data work-up differed between sections. For the parts of the guideline that have been updated by SR, the review methodology is outlined in detail in several ensuing publications $[5,6]$. In brief, SRs of the literature were conducted in accordance with PRISMA guidelines [3]. Important topics and questions were prioritised by the panel for the present update. For each SR, elements for inclusion and exclusion, including patient population, intervention, comparison, outcomes (PICO), study design, and search terms and restrictions, were developed using an iterative process involving all members of the panel to achieve consensus. Where relevant, confounding variables were identified for each question to facilitate the assessment of nonrandomised studies. Individual literature searches were conducted separately for each update question using the following databases: Medline, Medline In-Process, Embase, Cochrane Controlled Trials Register (The Cochrane Library, Issue 10, October 2013), and the Latin American and Caribbean Center on Health Sciences Information (LILACS). In addition, SRs and other background information were identified by searching the Cochrane Database of Systematic Reviews (The Cochrane Library, Issue 10, October 2013). The SR protocols containing details of the review process and search strategies used have been published on www.uroweb.org [7]. In addition, the reference lists of all the studies included were scanned to identify additional potentially relevant studies, and reports identified by the panel served as an additional source for

Table 1 - Description of the update and summary of the review methodology for 2014

\begin{tabular}{|c|c|}
\hline Chapter & Description of review methodology \\
\hline 1. Introduction & Not applicable \\
\hline 2. Epidemiology and aetiology & Updated using a structured data assessment \\
\hline 3. Diagnosis and staging & $\begin{array}{l}\text { Updated using a systematic review on tumour biopsy and a traditional narrative review for } \\
\text { the other aspects of diagnosis and staging }\end{array}$ \\
\hline 4. Classification and prognostic factors & Updated using a structured data assessment \\
\hline 5. Other renal tumours & $\begin{array}{l}\text { Updated using a traditional narrative review, based on a structured literature search; of } \\
\text { particular note is the inclusion of the new Vancouver Classification in the Histology section }\end{array}$ \\
\hline 6. Treatment of localised disease & $\begin{array}{l}\text { Updated using systematic reviews for management of small renal masses, lymph node } \\
\text { dissection, and local treatment of metastases } \\
\text { A new section, Management of RCC with venous thrombus, has been added that is based on } \\
\text { a systematic review }\end{array}$ \\
\hline 7. Systemic therapy for metastatic disease & Updated using a systematic review \\
\hline $\begin{array}{l}\text { 8. Surveillance following radical or partial } \\
\text { nephrectomy or ablative therapies }\end{array}$ & Updated based on a traditional narrative review, based on a structured data search \\
\hline
\end{tabular}


studies. In most instances the search was conducted up to the end of November 2013. Two independent reviewers screened abstracts and full texts, carried out data abstraction, and assessed the risk of bias (RoB). The results were presented in tables showing baseline characteristics and summaries of findings. Meta-analyses were performed only for randomised controlled trials (RCTs) if consistency and homogeneity of data were demonstrated. When this was not possible, a narrative synthesis of the evidence was provided. The remaining parts of the guideline have been updated using a traditional narrative review strategy.

References were assessed according to their level of scientific evidence (LE), and guideline recommendations were graded according to the 2009 Oxford Centre for Evidence-based Medicine Levels of Evidence (http://www. cebm.net/index.aspx?o=1025).

\section{Evidence synthesis}

The majority of the studies included in this guideline update are retrospective analyses that include some larger multicentre studies and well-designed controlled studies. As only a few RCTs are available, most of the data are not based on high levels of evidence. The exception was for systemic treatment of metastatic RCC ( $m R C C$ ), for which several RCTs have been performed, resulting in recommendations based on higher levels of evidence.

\subsection{Epidemiology and aetiology}

RCC represents 2-3\% of all cancers, with the highest incidence occurring in Western countries. In general, during the last two decades there has been an annual increase of approximately $2 \%$ in incidence both worldwide and in Europe until recently, with approximately 84400 new RCC cases and 34700 kidney cancer-related deaths within the European Union in 2012 [8]. In Europe, overall mortality rates for RCC increased up until the early 1990s, with rates generally stabilising or declining thereafter [9]. There has been a decrease in mortality since the 1980s in Scandinavian countries and since the early 1990s in France, Germany, Austria, the Netherlands, and Italy. However, in some European countries (Croatia, Estonia, Greece, Ireland, Slovakia), mortality rates still show an upward trend. with increasing rates [9]. RCC is the most common solid lesion within the kidney and accounts for approximately $90 \%$ of all kidney malignancies. It comprises different RCC subtypes with specific histopathological and genetic characteristics [10]. There is a 1.5:1 predominance in men over women, with peak incidence occurring between 60 and $70 \mathrm{yr}$ of age. Aetiological factors include lifestyle variables such as smoking, obesity, and hypertension [11]. Having a firstdegree relative with kidney cancer is also associated with an increased risk of RCC. A number of other factors have been suggested as being associated with higher or lower risk of RCC, but have not been confirmed. These include specific dietary habits and occupational exposure to specific carcinogens, but the literature is inconclusive [12]. Moderate alcohol consumption appears to have a protective effect for reasons not yet known [13]. The most effective prophylaxis is to avoid cigarette smoking and reduce obesity. Currently, more than 50\% of RCCs are detected incidentally when abdominal ultrasound (US) or computed tomography (CT) is carried out for other medical reasons (LE 3). This has led to an increase in the incidence of small renal masses (RMs), defined as contrast-enhancing masses with a greatest dimension of $4 \mathrm{~cm}$ or less on abdominal imaging [14].

\subsection{Diagnosis and staging}

\subsubsection{Symptoms}

Many patients with RMs remain asymptomatic until the late stages of the disease. It has been reported that the prevalence of the classic triad of flank pain, gross haematuria, and a palpable abdominal mass in some parts of the world is lower than previously observed (now 6-10\%) and correlates with advanced disease and subtypes associated with poor prognosis (LE 3) [15]. Paraneoplastic syndromes are found in approximately $30 \%$ of patients with symptomatic RCCs (LE 4). A few patients present with symptoms caused by mRCC, such as bone pain, deterioration of performance status (PS), or persistent cough (LE 3) [16].

\subsubsection{Imaging}

The traditional approaches for detecting and characterising RMs are US, CT, and magnetic resonance imaging (MRI; Table 2). RMs can be classified as solid or cystic on the basis of the imaging findings. For solid RMs, the most important criterion for differentiating malignant lesions is the presence of contrast enhancement or restriction on MRI (LE 3) [17]. Most RMs can be diagnosed accurately using imaging alone. Contrast-enhanced US can be helpful in specific cases (eg, chronic renal failure with a relative contraindication for iodinated or gadolinium contrast media, complex cystic masses, and differential diagnosis of peripheral vascular disorders such as infarction and cortical necrosis) (LE 3) [18]. However, CT and MRI features cannot reliably distinguish oncocytoma and fat-free angiomyolipoma from malignant renal neoplasms (LE 3) $[19,20]$. Advanced MRI techniques such as diffusionweighted and perfusion-weighted imaging are being explored in RM assessment [21]. Positron emission tomography (PET) is not currently a standard investigation (LE 3) [22]. In patients with RCC, chest CT is the most accurate investigation to diagnose lung metastases or enlarged mediastinal lymph nodes (LE 3) [23]. Since most bone and brain metastases mostly are symptomatic at diagnosis routine bone or brain imaging is only performed on indication (LE 3) [24]. In the case of a renal cystic mass, the Bosniak classification distinguishes five categories according to CT presentation. Bosniak classification can predict the risk of malignancy (LE 3) and provide guidance for management [25]. Bosniak 1, 2, 2F, 3, and 4 cysts are malignant in $0 \%, 0 \%, 25 \%, 54 \%$, and $100 \%$ of cases, respectively [26]. 
Table 2 - Key recommendations on diagnosis, staging, classification, and prognosis in patients with renal tumours

\begin{tabular}{|c|c|}
\hline Recommendation & GR \\
\hline $\begin{array}{l}\text { Contrast-enhanced multiphase abdominal CT and MRI are recommended for work-up of patients with RCC and are considered } \\
\text { equal for both staging and diagnosis }\end{array}$ & B \\
\hline $\begin{array}{l}\text { Contrast-enhanced multiphase abdominal CT and MRI are the most appropriate imaging modalities for renal tumour characterisation } \\
\text { and staging before surgery }\end{array}$ & C \\
\hline A chest $\mathrm{CT}$ is recommended for staging assessment of the lungs and mediastinum & C \\
\hline A bone scan is not routinely recommended & C \\
\hline A renal tumour biopsy is recommended before ablative therapy and systemic therapy without previous pathology & C \\
\hline A percutaneous biopsy is recommended in patients in whom active surveillance is pursued & C \\
\hline A percutaneous renal tumour biopsy should be obtained with a coaxial technique & C \\
\hline Use of the current TNM classification system is recommended. & B \\
\hline Grading systems and classification of RCC subtype should be used & B \\
\hline Prognostic risk models should be used in the metastatic setting & B \\
\hline
\end{tabular}

\subsubsection{Renal biopsy}

Percutaneous renal tumour biopsies are increasingly being used (1) for histological diagnosis of radiologically indeterminate RMs to avoid surgery in the event of benign lesions; (2) to select patients with small RMs for surveillance approaches; (3) to obtain histology before ablative treatments; and (4) to select the most suitable medical and surgical treatment strategy in the setting of mRCC (LE 3) [27-29]. Needle core biopsies are preferable for solid RMs in comparison with fine needle aspiration (LE 2b). Core biopsies should be performed with $18 \mathrm{G}$ needles and a coaxial technique to minimise the risk of complications and seeding (LE 2b) [28,30,31]. Either a US- or CT-guided approach can be used according to tumour and patient characteristics (LE 2b) [28,30]. At least two quality cores (nonfragmented, $>10 \mathrm{~mm}$ in length) should be obtained, and necrotic areas should be avoided to maximise diagnostic accuracy (LE 4) [30,32]. Peripheral biopsies are preferable for larger tumours to avoid the central necrosis (LE 2b) [33]. Core biopsies of solid RMs have shown a diagnostic yield of 78-97\%, with high specificity (98-100\%) and high sensitivity (86-100\%) for the diagnosis of malignancy (LE 2b) [34]. However, it has been reported that core biopsies are nondiagnostic in $2.5-22.0 \%$ of cases (LE 2b) [34]. If a biopsy is nondiagnostic but there are radiological findings suspicious for malignancy, a further biopsy or surgical exploration should always be considered (LE 4). Owing to the high diagnostic accuracy of current imaging, a biopsy is not necessary in the setting of localised or locally advanced disease before surgical treatment in fit patients with a long life expectancy and a highly suspicious, contrast-enhancing RM on CT or MRI (LE 4). Core biopsies should not be recommended for cystic RMs, unless areas with a solid pattern are present (Bosniak 4 cysts; LE 2b) $[28,30]$.

\subsubsection{Histological diagnosis}

Renal neoplasms comprise a broad spectrum of histopathological entities described in the 2004 WHO classification and modified by the International Society of Urological Pathology (ISUP) Vancouver Classification (Section 3.4) [35]. From a clinical viewpoint, three main RCC subtypes are important: clear cell RCC (ccRCC; 80-90\%), papillary RCC
(pRCC types I and II; 10-15\%, of which 60-70\% are type I), and chromophobe RCC (chRCC; 4-5\%). There are differences in tumour stage, grade, and cancer-specific survival (CSS) between RCC subtypes, and they have an impact on prognosis (Section 3.3). The 5-yr overall survival (OS) for all RCC subtypes is $49 \%$, which has further improved since 2006, probably because of an increase in incidentally detected RCCs and the introduction of targeted therapies [36]. Sarcomatoid differentiation can be found in all RCC subtypes and is equivalent to high-grade and very aggressive tumours (Section 3.4). Collecting duct carcinoma and other infrequent renal tumours are discussed in Section 3.4 (Table 3).

\subsection{Classification and prognostic factors}

\subsubsection{TNM stage classification}

The latest version of the TNM classification was published in 2010 and should be used for clinical and scientific staging purposes. The prognostic value of the 2010 TNM classification has been validated in both single- and multiinstitutional studies [37]. However, the subclassification of T1 tumours using a cutoff of $4 \mathrm{~cm}$ might not be optimal with the widening indication for nephron-sparing surgery for localised RCC. In addition, the value of size stratification of T2 tumours has been questioned [38]. In comparison to the 2009 version, there is no longer any distinction between $\mathrm{N} 1$ metastasis in a single regional lymph node and N2 metastases in more than one regional lymph node. Instead, N1 comprises metastasis in regional lymph node(s) [37].

\subsubsection{Prognostic factors}

Prognosis is influenced by anatomical, histological, clinical, and molecular factors. Anatomical factors are reflected in the TNM classification and provide the most reliable prognostic information. In addition, objective anatomical classification systems such as the Preoperative Aspects and Dimensions Used for an Anatomical (PADUA) classification system, the RENAL nephrometry score, and the C-index have been proposed to standardise the description of renal tumours and aid in comparing nephron-sparing treatment strategies [39-41]. Histological factors include nuclear grade, RCC subtype, sarcomatoid features, microvascular 
Table 3 - Summary of other renal tumours with an indication of malignant potential and recommendation for treatment (all grade C)

\begin{tabular}{|c|c|c|}
\hline Entity & Malignant potential & Treatment of localised tumour \\
\hline Sarcomatoid variants of RCC & High & Surgery \\
\hline Multilocular clear cell RCC & Low, no metastasis & Surgery, NSS \\
\hline Carcinoma of the collecting ducts of Bellini & High, very aggressive & Surgery, discussable for $\mathrm{M}+$ tumours \\
\hline Renal medullary carcinoma & High, very aggressive & Surgery \\
\hline Translocation RCC Xp11.2 & High & Surgery \\
\hline Translocation RCC t(6;11) & Low & Surgery, NSS \\
\hline Tubulocystic RCC & Low & Surgery, NSS \\
\hline Mucinous tubular and spindle cell carcinoma & Intermediate & Surgery, NSS \\
\hline Acquired cystic disease-associated RCC & Low & Surgery \\
\hline Clear cell (tubulo) papillary RCC & Low & Surgery, NSS \\
\hline Hybrid oncocytic chromophobe tumour & Low & Surgery, NSS \\
\hline Metanephric tumours & Benign & Surgery, NSS \\
\hline Cystic nephroma/mixed epithelial and stromal tumour & Low/benign & Surgery, NSS \\
\hline Oncocytoma & Benign & Observation (when histologically confirmed)/surgery, NSS \\
\hline Hereditary kidney tumours & High & Surgery, NSS \\
\hline Angiomyolipoma & Benign & Consider treatment only in very well-selected patients \\
\hline Unclassified RCC & Variable & Surgery, NSS \\
\hline
\end{tabular}

invasion, tumour necrosis, and invasion of the collecting system. Although affected by intra- and interobserver discrepancies, grade remains an independent prognostic factor [42]. At the ISUP conference, a simplified nuclear grading system, based only on the size and shape of nucleoli, was proposed to replace the Fuhrman grading system [35]. Regarding RCC subtypes, there is a trend in univariate analysis towards better prognosis for patients with chRCC versus pRCC (with pRCC type II worse than ccRCC) versus ccRCC [43]. However, the prognostic information provided by RCC subtype is lost when stratified to tumour stage (LE 3) [43]. For localised RCC, several risk scores and nomograms can be used, including the Stage, Size, Grade, and Necrosis Score (SSIGN) [44], a modified version of the SSIGN score (Leibovich score) [45], the University of California Los Angeles Integrated Staging System (UISS) [46], and Karakiewicz's nomogram (LE 3) [47]; Section 3.7 provides further details. Clinical factors include patient PS, localised symptoms, cachexia, anaemia, elevated neutrophil and platelet counts, and other laboratory parameters, and are predominantly used in prognostic risk models in mRCC (LE 3) [48,49]. Numerous molecular markers including gene expression profiling and deep and whole-genome-wide sequencing have been investigated, but none of these techniques has yet yielded markers or profiles that improve the predictive accuracy of current prognostic systems. Their use is therefore not recommended in routine practice. There is hope that molecular techniques will augment the current pre- and postoperative prognostic nomograms and the risk scores for mRCC, which have $\mathrm{C}$-indices of $0.63-0.84$ and have reached a plateau in accuracy based on histological and clinical factors [49].

\subsection{Other renal tumours}

A revised histopathological classification was published in 2013 as the ISUP Vancouver classification of renal neoplasia [35]. This classification will probably constitute the basis of the new WHO classification to replace the 2004 version.
The common RCC subtypes (Section 3.2.4.) account for $85-90 \%$ of renal malignancies. The remaining $10-15 \%$ of renal tumours include renal pelvis carcinoma and a variety of uncommon, sporadic, and familial carcinomas, some of which have recently been described, and a group of unclassified carcinomas. For these generally rare renal tumours, Table 3 summarises their malignant potential and universal grade $\mathrm{C}$ recommendations for treatment, if localised. Extensive details are provided in the full guidelines [4].

\subsection{Treatment of localised RCC and local treatment of mRCC}

Six SRs underpin the recommendations of this section (Supplementary Table 1) [7]. These reviews included all relevant published literature comparing surgical management of localised RCC (T1-2N0M0) [50,51], different strategies for small RMs, lymphadenectomy and adrenalectomy [6], caval venous thrombus, and local therapy of metastases from RCC. Owing to the very limited number of RCTs, nonrandomised studies (NRSs), prospective observational studies with controls, retrospective matched-pair studies, and comparative studies from the databases of well-defined registries were also included. Studies with no comparator group (eg, case series), unmatched retrospective studies, and chart reviews were excluded because of their inherent RoB.

\subsubsection{Surgical treatment}

For localised RCC, surgery is the only curative treatment with high-quality evidence. According to oncological and quality-of-life outcomes, localised T1a-b tumours are best managed by partial nephrectomy (PN) rather than radical nephrectomy (RN), if technically feasible, irrespective of the surgical approach (LE 1b; Table 4). A prospective RCT compared RN with PN in solitary T1a-b NOM0 renal tumours $<5 \mathrm{~cm}$ with normal contralateral kidney function and WHO PS 0-2. At 9.3-yr follow-up, 198 patients (72.5\%) were alive after RN and 173 (64.4\%) after PN, with CSS of $98.5 \%$ and $97 \%$, respectively. Local recurrence occurred in 
Table 4 - Key recommendations for treatment of localised RCC and local treatment of metastatic RCC

\begin{tabular}{|c|c|}
\hline Recommendation & GR \\
\hline Nephron-sparing surgery is recommended in patients with T1a tumours & A \\
\hline Nephron-sparing surgery should be favoured over radical nephrectomy in patients with T1b tumours when technically feasible & B \\
\hline Ipsilateral adrenalectomy is not recommended when there is no clinical evidence of invasion of the adrenal gland & B \\
\hline Lymph node dissection is not recommended for localised tumours without clinical evidence of lymph node invasion & A \\
\hline In patients with clinically enlarged lymph nodes, lymph node dissection can be performed for staging purposes or local control & C \\
\hline $\begin{array}{l}\text { Laparoscopic radical nephrectomy is recommended for patients with T2 tumours and localised renal masses not treatable by } \\
\text { nephron-sparing surgery }\end{array}$ & B \\
\hline Owing to the low quality of the available data, no recommendation can be made on radiofrequency ablation or cryoablation & C \\
\hline $\begin{array}{l}\text { In the elderly and/or comorbid patients with small renal masses and limited life expectancy, active surveillance, radiofrequency } \\
\text { ablation, and cryoablation can be offered }\end{array}$ & C \\
\hline Cytoreductive nephrectomy is recommended in appropriately selected patients with metastatic RCC & C \\
\hline Bosniak cysts greater than type III should be regarded as RCC and be treated accordingly & C \\
\hline
\end{tabular}

one patient in the RN group and six patients in the PN group [52]. Many retrospective studies compared PN to RN (open or laparoscopic) for $\mathrm{RCC}<4 \mathrm{~cm}[4,50,53]$ and demonstrated an association between RN and increased cardiovascular events and mortality from any cause after adjusting for patient characteristics. In studies analysing RCCs of 4-7 cm, no CSS differences were observed between PN and RN [50]. No prospective comparative studies were identified reporting on oncological outcomes for minimally invasive ablative procedures compared with RN. One trial reported on radiofrequency ablation (RFA) versus RN or PN for T1a RCC; CSS of $100 \%$ was observed for each of the three treatment modalities [50]. If PN is not feasible, the curative therapy remains $\mathrm{RN}$, which includes removal of the tumour-bearing kidney. Complete resection of the primary tumour with PN or RN performed via either open or laparoscopic surgery offers a reasonable chance of cure. Ipsilateral adrenalectomy during RN or PN does not provide a survival advantage (LE 3). In patients with localised disease and no clinical evidence of lymph node metastases, there is no proof of any survival advantage of lymph node dissection (LE 1b). In patients with localised disease and clinically enlarged lymph nodes, the survival benefit of lymph node dissection is not demonstrated. However, such dissection can be performed for staging purposes (LE 3).

\subsubsection{RN techniques}

There are no RCTs assessing oncological outcomes of laparoscopic RN versus open RN. A prospective cohort study and several retrospective database reviews are available, mostly of low methodological quality. These studies showed similar oncological outcomes for laparoscopic versus open RN, but a significantly shorter hospital stay and lower analgesic requirement for the laparoscopic compared with the open group [50,51]. On the basis of these data, laparoscopic RN has lower morbidity compared to open surgery (LE 1b). Similar oncological outcomes were reported for both retroperitoneal and transperitoneal approaches in two RCTs and one quasi-randomised study [54]. No reliable comparative data exist with regard to hand-assisted, robotic, and laparoendoscopic single-site nephrectomy versus the conventional laparoscopic approach.

\subsubsection{PN techniques}

Studies comparing laparoscopic PN and open PN found no difference in progression-free survival (PFS) or OS between the techniques in centres with laparoscopic expertise [55-57]. The mean estimated blood loss was generally lower with the laparoscopic approach, but warm ischaemia time (WIT) was prolonged [56]. In a matchedpair comparison, the decline in glomerular filtration rate was greater in the laparoscopic PN group in the immediate postoperative period [55], but not after a follow-up of 3.6 yr. Retroperitoneal and transperitoneal laparoscopic PN yielded similar perioperative outcomes. In a large, retrospective, multicentre comparative study, simple tumour enucleation had similar PFS and CSS rates to standard PN and RN [58]. At present, no study has compared the oncological outcomes of robot-assisted versus laparoscopic PN. A prospective comparison of surgical outcomes obtained after robotic or pure laparoscopic PN in moderate to complex renal tumours showed significantly lower estimated blood loss and shorter WIT in the robotic group [59]. Meta-analyses of relatively small series found comparable perioperative outcomes and shorter WIT for robot-assisted PN [60]. In conclusion, PN can be performed, either with an open, pure laparoscopic, or robot-assisted approach, according to the surgeon's expertise and skills and equipment availability (LE 2b).

\subsubsection{Management of RCC with venous thrombus}

An RCC tumour thrombus in the inferior vena cava (IVC) is a significant adverse prognostic factor (Section 3.3.1.). Traditionally, patients with venous tumour thrombus (VTT) usually undergo RN and thrombectomy. Aggressive surgical resection is widely accepted as the default management for VTT [61]. However, uncertainties remain regarding the surgical treatment, especially in terms of comparative effectiveness and harms. There is variation in how the surgery is undertaken in terms of preoperative strategies (eg, use of IVC filter or preoperative embolisation), the surgical approach for IVC access, and bypass procedures to achieve vascular control (eg, venovenous bypass or cardiopulmonary bypass and deep hypothermic circulatory arrest). To determine the evidence base for these different strategies, an SR of the literature was undertaken, including 
comparative studies only reporting on management of VTT in non-mRCC (nmRCC; Supplementary Table 1) [7]. Only five retrospective studies [4] were eligible for inclusion, all with significant RoB, none of which addressed the question of whether patients with nmRCC and VTT derive a benefit from surgery to remove the thrombus, and how thrombectomy influences prognosis from an oncological perspective. Nevertheless, the findings support the notion that all patients with nmRCC and VTT should be considered for surgical intervention, irrespective of the extent of tumour thrombus at presentation (LE 3). PS can significantly improve after removal; therefore, deterioration of PS due to thrombus should not be an exclusion criterion for surgery, There is no distinct surgical method that seems superior for VTT excision, although the surgical method appears to depend on the VTT level and the grade of occlusion of the IVC. For adequate removal of the thrombus, caval vein control is key, which may require liver mobilisation and cardiac bypass. Preoperative embolisation does not seem to have any clinical value. The relative benefits and harms of other strategies and approaches regarding IVC access and the role of IVC filters and bypass procedures remain uncertain.

\subsubsection{Therapeutic approaches as alternatives to surgery}

3.5.5.1. Embolisation. Before a routine nephrectomy, there is no benefit in performing tumour embolisation [62]. In patients unfit for surgery and suffering from massive haematuria or flank pain, embolisation can be a beneficial palliative intervention (LE 3).

3.5.5.2. Surveillance. Elderly and comorbid patients with incidentally detected small RMs have relatively low RCCspecific mortality and significant competing-cause mortality [63]. Active surveillance can be offered to this category of patients and is defined as initial monitoring of tumour size via serial abdominal imaging (US, CT, or MRI), with delayed intervention reserved for tumours that show clinical progression during follow-up. As mentioned, a renal biopsy is recommended before inclusion of patients in surveillance approaches (LE 3). In the largest reported active surveillance series, RM growth was low (average $0.13 \mathrm{~cm} / \mathrm{yr}$ ) in most cases and progression to mRCC was rare (1-2\%; LE 3 ) [63]. The frequency of serial imaging in this study consisted of CT, MRI, or US at 3 and 6 mo, then every 6 mo until $3 \mathrm{yr}$, and then annually (LE 3 ).

3.5.5.3. Ablative therapies. The most commonly performed minimally invasive approaches besides surgery include percutaneous RFA, laparoscopically assisted or percutaneous cryoablation (CA), microwave ablation, stereotactic radiosurgery, laser ablation, and high-intensity focused US ablation. With the exception of RFA and CA, most approaches are experimental. Indications for thermal ablation include small RMs in elderly comorbid patients considered unfit for surgery, those with a genetic predisposition to develop multiple tumours, and patients with bilateral tumours or with a solitary kidney and a high risk of complete loss of renal function following PN. Larger tumours or those located at the hilum or near the proximal ureter are not recommended for ablation. There are no RCTs comparing RFA or CA with PN. Low-quality studies suggest a higher local recurrence rate for thermal ablation compared with PN (LE 3). The quality of the available data does not allow any definitive conclusions regarding morbidity and oncological outcomes for RFA and CA (LE3) [64].

\subsubsection{Adjuvant therapy}

Several phase 3 RCTs of adjuvant sunitinib, sorafenib, pazopanib, axitinib, and everolimus are ongoing. Until results from these studies are reported, there is no evidence to support the use of adjuvant therapy after RCC surgery. Prior RCTs with cytokines, chemotherapy, or vaccines were largely negative [65].

\subsubsection{Surgical treatment of mRCC (cytoreductive nephrectomy)} RCC surgery is curative only if all the tumour burden can be removed. Retrospective data suggest that this goal is achievable in patients with single- or oligometastatic disease that is amenable to surgery. For most patients with mRCC, cytoreductive nephrectomy $(\mathrm{CN})$ is palliative and systemic treatment is necessary. In a meta-analysis of two RCTs comparing CN plus immunotherapy versus immunotherapy alone, there was a significant increase in long-term survival in patients treated with CN [66]. At present, only retrospective data are available for comparison of $\mathrm{CN}$ combined with targeted agents to systemic therapy alone; these data suggest that patients with good PS or risk scores may benefit from surgery [67]. Results for the randomised phase 3 CARMENA and EORTC SURTIME studies are awaited. $\mathrm{CN}$ is currently recommended in mRCC patients with good PS, large primary tumours, and low metastatic volume. In patients with poor PS or International mRCC Database Consortium (IMDC) risk, those with small primaries and high metastatic volume and/or a sarcomatoid tumour, $\mathrm{CN}$ is not recommended.

\subsubsection{Local therapy of metastases in RCC}

An SR was undertaken of all types of comparative study on local treatment of metastases from RCC in any organ (Supplementary Table 1) [68]. Relevant interventions included metastasectomy, various radiotherapy modalities, and no local treatment [7]. The outcomes were survival (OS, CSS, and PFS), local symptom control, and adverse events. All studies included were retrospective, nonrandomised, comparative studies, resulting in high RoB associated with nonrandomisation, attrition, and selective reporting [68]. With the exception of brain and possibly bone metastases frequently treated by stereotactic radiotherapy, metastasectomy remains by default an appropriate local treatment for most sites. Retrospective comparative studies consistently point towards a benefit of complete metastasectomy in mRCC patients in terms of OS, CSS, and delay of systemic therapy. Radiotherapy, especially stereotactic radiotherapy, for bone and brain metastases from RCC can induce significant relief from local symptoms (all LE 3). 


\subsection{Systemic therapy for mRCC}

An SR was undertaken to analyse evidence for first and subsequent lines of treatment, combinations, and RCC subtypes (Supplementary Table 1) [5,7].

\subsubsection{Clear-cell $m R C C$}

In patients with clear-cell (cc)-mRCC, chemotherapy is not effective. Recent advances in molecular biology have led to the development of several novel agents for treating mRCC (Table 5). As a consequence, monotherapy with interferon (IFN)- $\alpha$ or high-dose bolus interleukin (IL)-2 should no longer be routinely recommended as first-line therapy in mRCC, except in certain circumstances (eg, lung metastasis, cc-mRCC, long interval). In sporadic cc-mRCC, hypoxia-inducible factor (HIF) accumulation due to von Hippel-Lindau (VHL) inactivation results in overexpression of vascular endothelial growth factor (VEGF) and plateletderived growth factor (PDGF), both of which promote neoangiogenesis [69]. This process substantially contributes to the development and progression of RCC. At present, there are seven targeted drugs approved in the USA and Europe for treating mRCC: sorafenib; sunitinib; bevacizumab combined with IFN- $\alpha$; pazopanib; temsirolimus; everolimus; and axitinib. A detailed review of the registration trials is available in the online guideline [4]. Since the Memorial Sloan-Kettering Cancer Center (MSKCC) (Motzer) criteria were developed during the cytokine era [70], the IMDC has established and validated a risk model for patients treated in the era of targeted therapy that should be preferred. Neutrophilia and thrombocytosis have been added to the list of MSKCC risk factors, while lactate dehydrogenase (LDH) has been removed [49]. To accurately select treatment for patients, risk stratification according to prognostic scores should be performed and the subtype should be established (LE 1b based on results of RCTs using risk stratification $[5,71,72]$ ). Pivotal phase 3 trials have established sunitinib and bevacizumab plus IFN- $\alpha$ as first-line treatment options in treatment-naïve patients with cc-mRCC and good to intermediate risk [71,72]. The COMPARZ study, which had a noninferiority design, demonstrated that pazopanib and sunitinib have similar efficacy but different toxicity profiles [73]. The study therefore firmly established pazopanib as another first-line option. On the basis of trial results and limitations in study design, axitinib is not approved for therapy of treatment-naïve mRCC. For patients with (modified) poor-risk mRCC, an RCT demonstrated longer PFS and OS for temsirolimus compared to IFN- $\alpha$ alone or combined with temsirolimus (LE 1b) [74]. Despite several attempts, combination therapy using currently approved targeted drugs did not demonstrate a benefit in comparison to single-agent use, mainly because of tolerability issues. Therefore, there is a need to sequence available agents according to RCT results [5]. Several phase 2 and 3 trials have investigated therapeutic options for patients who have progressed on cytokines and firstline VEGF-targeted therapy. Axitinib and everolimus both met their primary endpoints in randomised phase 3 trials (AXIS and RECORD-1) in the VEFG-resistant setting, and sorafenib is a reasonable treatment option. No firm recommendations can currently be made regarding the best sequence for targeted therapy [5]. The therapeutic recommendations and evidence base are summarised in Table 5. For a list of graded key recommendations, see Supplementary Table 2 .

Table 5 - European Association of Urology 2014 evidence-based recommendations for systemic therapy in patients with mRCC

\begin{tabular}{|c|c|c|c|c|c|c|c|c|c|}
\hline RCC type & $\begin{array}{c}\text { MSKCC } \\
\text { risk group [70] }\end{array}$ & First line & $\mathrm{LE}^{\mathrm{e}}$ & Second line ${ }^{a}$ & $\mathrm{LE}^{\mathrm{e}}$ & Third line $^{a}$ & $\mathrm{LE}^{\mathrm{e}}$ & Later lines & LE \\
\hline Clear cell $^{\mathrm{a}}$ & $\begin{array}{l}\text { Favourable, } \\
\text { intermediate, } \\
\text { and poor }\end{array}$ & $\begin{array}{l}\text { Sunitinib } \\
\text { Pazopanib } \\
\text { Bevacizumab + IFN } \\
\text { (favourable-intermediate } \\
\text { only) }\end{array}$ & $\begin{array}{l}1 \mathrm{~b} \\
1 \mathrm{~b} \\
1 \mathrm{~b}\end{array}$ & $\begin{array}{l}\text { After VEGFR: } \\
\text { Axitinib } \\
\text { Sorafenib }^{\mathrm{d}} \\
\text { Everolimus } \\
\text { After cytokines: } \\
\text { Sorafenib }{ }^{\mathrm{d}} \\
\text { Axitinib } \\
\text { Pazopanib }\end{array}$ & $\begin{array}{l}2 \mathrm{a} \\
2 \mathrm{a} \\
2 \mathrm{a} \\
\\
1 \mathrm{~b} \\
2 \mathrm{a} \\
2 \mathrm{a}\end{array}$ & $\begin{array}{l}\text { After VEGFR: } \\
\text { everolimus } \\
\text { After mTOR: } \\
\text { sorafenib }\end{array}$ & $\begin{array}{l}2 \mathrm{a} \\
1 \mathrm{~b}\end{array}$ & $\begin{array}{l}\text { Any } \\
\text { targeted } \\
\text { agent }\end{array}$ & 4 \\
\hline Clear cell ${ }^{\mathrm{a}}$ & Poor $^{\mathrm{c}}$ & Temsirolimus & $1 \mathrm{~b}$ & Any targeted agent & & & & & \\
\hline Nonclear cell ${ }^{\mathrm{b}}$ & Any & $\begin{array}{l}\text { Sunitinib } \\
\text { Everolimus } \\
\text { Temsirolimus }\end{array}$ & $\begin{array}{l}2 \mathrm{a} \\
2 \mathrm{~b} \\
2 \mathrm{~b}\end{array}$ & Any targeted agent & 4 & & & & \\
\hline
\end{tabular}

IFN = interferon; LE = level of evidence; MSKCC = Memorial Sloan-Kettering Cancer Center; mTOR = mammalian target of rapamycin inhibitor; mRCC = metastatic renal cell carcinoma; RCC = renal cell carcinoma; TKI = tyrosine kinase inhibitor; VEGFR = vascular endothelial growth factor receptor.

a Doses: IFN- $\alpha 9$ MU three times per week subcutaneously; bevacizumab $10 \mathrm{mg} / \mathrm{kg}$ biweekly intravenously; sunitinib $50 \mathrm{mg}$ daily orally for a period of 4 wk, followed by 2 wk of rest ( $37.5 \mathrm{mg}$ continuous dosing did not show significant differences); temsirolimus 25 mg weekly intravenously; pazopanib 800 mg daily orally; axitinib $5 \mathrm{mg}$ twice daily, to be increased to $7 \mathrm{mg}$ twice daily, unless greater than grade 2 toxicity, blood pressure $>150 / 90 \mathrm{~mm} \mathrm{Hg}$, or the patient is taking antihypertensive medication; everolimus $10 \mathrm{mg}$ daily orally.

b No standard treatment available. Patients should be treated in the framework of clinical trials. If a trial is not available, a decision can be made in consultation with

the patient to perform treatment in line with clear-cell renal cell carcinoma.

c Poor risk criteria in the NCT00065468 trial consisted of MSKCC [70] risk plus metastases in multiple organs.

d Sorafenib was inferior to axitinib in a RCT in terms of PFS but not OS (34).

e Level of evidence was downgraded in instances when data was obtained from subgroup analysis within an RCT. 
Table 6 - Proposed algorithm for risk-adapted surveillance following treatment for RCC

\begin{tabular}{|c|c|c|c|c|c|c|c|c|}
\hline \multirow[t]{2}{*}{ Risk profile } & \multirow[t]{2}{*}{ Treatment } & \multicolumn{7}{|c|}{ Surveillance } \\
\hline & & $6 \mathrm{mo}$ & $1 \mathrm{yr}$ & $2 \mathrm{yr}$ & $3 \mathrm{yr}$ & $4 \mathrm{yr}$ & $5 \mathrm{yr}$ & $>5 \mathrm{yr}$ \\
\hline Low & RN/PN only & US & CT & US & СТ & US & CT & Discharge \\
\hline Intermediate & RN/PN/CA/RFA & СT & СT & CT & US & CT & CT & CT once every $2 \mathrm{yr}$ \\
\hline High & $\mathrm{RN} / \mathrm{PN} / \mathrm{CA} / \mathrm{RFA}$ & CT & CT & CT & CT & CT & CT & CT once every $2 \mathrm{yr}$ \\
\hline
\end{tabular}

$\mathrm{CA}=$ cryoablation; $\mathrm{CT}=$ computed tomography of chest and abdomen; $\mathrm{MRI}=$ magnetic resonance imaging; $\mathrm{PN}$ = partial nephrectomy; RFA = radiofrequency ablation; RN = radical nephrectomy; US = ultrasound of abdomen, kidneys, and renal bed.

\subsubsection{Non-clear-cell $m R C C$}

No phase 3 trials on systemic treatment of patients with non-clear-cell (ncc)-mRCC have been reported. Expanded access programs and subset analysis from RCC studies suggest that the outcome of targeted therapy in these patients is inferior to that for cc-mRCC. Targeted treatment in ncc-mRCC has focused on temsirolimus, everolimus, sorafenib, and sunitinib, and data have been reported from single-arm phase 2 trials [5]. A randomised phase 2 trial of everolimus versus sunitinib with crossover design in nccmRCC included 73 patients ( 27 with pRCC) and was stopped after a futility analysis for PFS and OS. Median OS for everolimus was 10.5 mo but was not reached for sunitinib [75]. The final results presented at the 2014 annual meeting of the American Society of Clinical Oncology showed a nonsignificant trend favouring sunitinib. Both sunitinib and everolimus remain options in this population, with a preference for sunitinib. Patients with ncc-mRCC should be referred to a clinical trial where appropriate.

\subsection{Surveillance following nephrectomy or ablative therapies}

Surveillance after treatment for RCC allows the clinician to monitor or identify postoperative complications, renal function, local recurrence after PN or ablation, recurrence in the contralateral kidney, and development of metastases. Since the last guideline update was published in 2010, the evidence base for follow-up strategies has not changed [2]. There is a clear need for further research to determine whether follow-up benefits patient survival, to identify the time point at which restaging has the best chance of detecting recurrence, and to develop prognostic markers at surgery for the risk of relapse over time. The current conclusions are that the aim of surveillance is to detect either de novo lesions in the kidney or local recurrence or metastases while the patient is still surgically curable. In addition, renal function should be assessed. To tailor follow-up and avoid unnecessary intensive surveillance with imaging, risk stratification should be based on risk assessment scores. Despite validation, none of the proposed models or nomograms is $100 \%$ accurate, with C-indices ranging from $74 \%$ to $82.2 \%$ for assessment of recurrence and from $68 \%$ to $89 \%$ for assessment of cancer-specific mortality [76]. A commonly used model is the UISS integrated staging system using TNM stage, Eastern Cooperative Oncology Group PS, and nuclear grade [46,77]. The SSIGN score adds necrosis and tumour size and has been modified by Leibovich $[44,45]$. Overall, because of a lack of $100 \%$ accuracy, historical differences in the use of TNM staging systems, and differences in assessments (OS, CSS, mortality, recurrence-free survival) and subtypes (ccRCC only vs all subtypes), no preference for a risk stratification model can be given. A plateau has been reached in accuracy and a certain error rate has to be accepted for all models. However, the risk groups established for low, intermediate, and high risk allow tailoring of follow-up protocols, and one of the models should be chosen for use in routine clinical practice. The following recommendations can be made based on LE 4: (1) for low-risk disease, cross-sectional imaging (CSI) with CT/MRI can be used infrequently; (2) in the intermediate-risk group, intensified follow-up should be performed, including CSI at regular intervals; and (3) in high-risk patients, follow-up examinations should include routine CSI in the first few years following treatment. There is an increased risk of intrarenal recurrence in larger $(>7 \mathrm{~cm})$ tumours treated with $\mathrm{PN}$, or when there is a positive margin. Follow-up should be intensified in such patients. Table 6 proposes a risk-adapted follow-up algorithm.

\section{Conclusions}

These updated 2014 guidelines provide the current evidence base for the management of RCC according to the most robust and reliable standards. In contrast to previous versions, a multidisciplinary panel prioritised the importance of specific topics and questions, for which evidence synthesis was performed based on SRs. In addition, guideline recommendations were graded according to the 2009 Oxford Centre for Evidence-based Medicine Levels of Evidence. The aim of the panel is to strengthen the methodological quality of evidence synthesis to further improve the overall quality of the guideline and its recommendations, which in turn will enhance its dissemination and uptake and its impact on patients, clinicians, and health care organisations.

Author contributions: Axel Bex had full access to all the data in the study and takes responsibility for the integrity of the data and the accuracy of the data analysis.

Study concept and design: Ljungberg, Bensalah, Canfield, Dabestani, Hoffmann, Hora, Kuczyk, Lam, Marconi, Merseburger, Mulders, Powles, Staehler, Volpe, Bex.

Acquisition of data: Ljungberg, Bensalah, Canfield, Dabestani, Hoffmann, Hora, Kuczyk, Lam, Marconi, Merseburger, Mulders, Powles, Staehler, Volpe, Bex. 
Analysis and interpretation of data: Ljungberg, Bensalah, Canfield, Dabestani, Hoffmann, Hora, Kuczyk, Lam, Marconi, Merseburger, Mulders, Powles, Staehler, Volpe, Bex.

Drafting of the manuscript: Bex.

Critical revision of the manuscript for important intellectual content: Ljungberg, Bensalah, Canfield, Dabestani, Hoffmann, Hora, Kuczyk, Lam, Marconi, Merseburger, Mulders, Powles, Staehler, Volpe, Bex.

Statistical analysis: Ljungberg, Bensalah, Canfield, Dabestani, Hoffmann, Hora, Kuczyk, Lam, Marconi, Merseburger, Mulders, Powles, Staehler, Volpe, Bex.

Obtaining funding: None.

Administrative, technical, or material support: None.

Supervision: Bex, Ljungberg.

Other: None.

Financial disclosures: Axel Bex certifies that all conflicts of interest, including specific financial interests and relationships and affiliations relevant to the subject matter or materials discussed in the manuscript (eg, employment/affiliation, grants or funding, consultancies, honoraria, stock ownership or options, expert testimony, royalties, or patents filed, received, or pending), are the following: Borje Ljungberg has received speaker honoraria from GSK, Roche, Pfizer, and Novartis, has participated in trials by GSK, Medivation, Pfizer, and Janssen, and is on advisory boards for Pfizer and GSK. Axel Bex has received research grants and speaker honoraria from Pfizer, and is a consultant for Pfizer and Novartis. Steven Canfield has received speaker honoraria from Bayer, Algeta, Genomic Health, and Amgen. Milan Hora has received grants or research support from Ipsen and speaker honoraria from Astellas, Janssen, Olympus, and Covidien, and has participated in trials by Janssen. Markus A. Kuczyk has received grants or research support from Wyeth and Pfizer, and speaker honoraria from Jansen Cilag, Hexal, Pierre Fabre, GSK, Bayer, Astellas, and Pfizer, participated in trials by Janssen, Ipsen, Astellas, Protect Study, and Millenium Study C21004 and C21005, is a consultant for Storz, Hexal, Astellas, AstraZeneca, and Coloplast, and owns shares in Wyeth, Pfizer, Storz, Astellas, Bayer, and Novartis. Thomas Lam has received speaker honoraria from and is a consultant for Ipsen, Astellas, GSK, and Pfizer. Axel S. Merseburger has received grants or research support from Wyeth and speaker honoraria from Novartis, Astellas, SEP, Pfizer, Wyeth, and Ipsen Pharma, has participated in speaker bureaus for Astellas, Pfizer, Janssen, Teva, Novartis, and Ferring, and trials by Novartis, Astellas, Teva, Pfizer, Bayer, and AstraZeneca, and is a consultant for Janssen Cilag, Astellas, Pfizer, Novartis, Bayer, and Ipsen Pharma. Peter Mulders has received grants or research support from Bayer, Pfizer, GSK, Wilex, and Astellas, and speaker honoraria from GSK, Novartis, Pfizer, Astellas, J\&J, and AstraZeneca, and has participated in trials by Provenge, J\&J, GSK, Pfizer, Astellas, and Milenium. Thomas Powles has received grants or research support from GSK, Pfizer, Astellas, GSK, Roche, Pfizer, and Novartis, and speaker honoraria from Novartis, Pfizer and GSK, has participated in trials by GSK, Pfizer, and BMS, and is a consultant for Novartis, Pfizer, and GSK. Michael Staehler has received grants or research support and fellowship or travel grants from GSK, Roche, Pfizer, and Novartis, and speaker honoraria from Astellas, GSK, Roche, Pfizer, and Novartis, has participated in trials by GSK, Roche, Pfizer, and Novartis, and is a consultant for Astellas, GSK, Roche, Pfizer, and Novartis. Karim Bensalah, Saeed Dabestani, Fabian Hofmann, Lorenzo Marconi and Alessandro Volpe have nothing to disclose.

Funding/Support and role of the sponsor: None.

Acknowledgments: The EAU RCC Guideline Panel is most grateful for scientific support provided by the following: Prof. Dr. O. Hes (pathologist, Pilzen, Czech Republic) for Chapter 5 (Other renal tumours); Dr. T. Adewuyi (Aberdeen, UK) for systematic review of systemic therapy for metastatic disease and for providing general assistance with various aspects of the systematic review work; Dr. H. Bekema (Groningen, Netherlands) for systematic review of lymph node dissection in localised and locally advanced RCC; Dr. F. Stewart (Aberdeen, UK) for systematic review of venous tumour thrombus; Prof. Dr. A. Graser (radiologist, Munich, Germany) for development of a systematic review for diagnosis and follow-up chapters (in progress); and Prof. Dr. John Norrie (statistician, Aberdeen, UK) for systematic review and meta-analysis of tumour biopsy.

\section{Appendix A. Supplementary data}

Supplementary data associated with this article can be found, in the online version, at http://dx.doi.org/10.1016/j. eururo.2015.01.005.

\section{References}

[1] Mickisch G, Carballido J, Hellsten S, Schulze H, Mensink H. Guidelines on renal cell cancer. Eur Urol 2001;40:252-5.

[2] Ljungberg B, Cowan NC, Hanbury DC, et al. EAU guidelines on renal cell carcinoma: the 2010 update. Eur Urol 2010;58:398-406.

[3] Moher D, Liberati A, Tetzlaff J, Altman DG. Preferred reporting items for systematic reviews and meta-analyses: the PRISMA statement. J Clin Epidemiol 2009;62:1006-12.

[4] Ljungberg B, Bensalah K, Bex A, et al. Guidelines on renal cell carcinoma. European Association of Urology; 2014, www. uroweb.org.

[5] Albiges L, Choueiri T, Escudier B, et al. A systematic review of sequencing and combinations of systemic therapy in metastatic renal cancer. Eur Urol 2015;67:100-10.

[6] Bekema HJ, MacLennan S, Imamura M, et al. Systematic review of adrenalectomy and lymph node dissection in locally advanced renal cell carcinoma. Eur Urol 2013;64:799-810.

[7] Ljungberg B, Bensalah K, Bex A, et al. Systematic review methodology for the European Association of Urology Guidelines for renal cell carcinoma (2014 update). http://www.uroweb.org/gls/EU/ Systematic_methodology_RCC_2014_update.pdf

[8] Ferlay J, Steliarova-Foucher E, Lortet-Tieulent J, et al. Cancer incidence and mortality patterns in Europe: estimates for 40 countries in 2012. Eur J Cancer 2013;49:1374-403.

[9] Levi F, Ferlay J, Galeone C, et al. The changing pattern of kidney cancer incidence and mortality in Europe. BJU Int 2008;101:949-58.

[10] Kovacs G, Akhtar M, Beckwith BJ, et al. The Heidelberg classification of renal cell tumours. J Pathol 1997;183:131-3.

[11] Pischon T, Lahmann PH, Boeing $\mathrm{H}$, et al. Body size and risk of renal cell carcinoma in the European Prospective Investigation into Cancer and Nutrition (EPIC). Int J Cancer 2006;118:728-38.

[12] Daniel CR, Cross AJ, Graubard BI, et al. Large prospective investigation of meat intake, related mutagens, and risk of renal cell carcinoma. Am J Clin Nutr 2012;95:155-62.

[13] Bellocco R, Pasquali E, Rota M, et al. Alcohol drinking and risk of renal cell carcinoma: results of a meta-analysis. Ann Oncol 2012;23:2235-44.

[14] Gill IS, Aron M, Gervais DA, Jewett MA. Clinical practice. Small renal mass. N Engl J Med 2010;362:624-34.

[15] Patard JJ, Leray E, Rodriguez A, Rioux-Leclercq N, Guille F, Lobel B. Correlation between symptom graduation, tumor characteristics and survival in renal cell carcinoma. Eur Urol 2003;44:226-32.

[16] Kim HL, Belldegrun AS, Freitas DG, et al. Paraneoplastic signs and symptoms of renal cell carcinoma: implications for prognosis. J Urol 2003;170:1742-6.

[17] Israel GM, Bosniak MA. How I do it: evaluating renal masses. Radiology 2005;236:441-50.

[18] Mitterberger M, Pelzer A, Colleselli D, et al. Contrast-enhanced ultrasound for diagnosis of prostate cancer and kidney lesions. Eur J Radiol 2007;64:231-8. 
[19] Choudhary S, Rajesh A, Mayer NJ, Mulcahy KA, Haroon A. Renal oncocytoma: CT features cannot reliably distinguish oncocytoma from other renal neoplasms. Clin Radiol 2009;64:517-22.

[20] Hindman N, Ngo L, Genega EM, et al. Angiomyolipoma with minimal fat: can it be differentiated from clear cell renal cell carcinoma by using standard MR techniques? Radiology 2012; 265:468-77.

[21] Giannarini G, Petralia G, Thoeny HC. Potential and limitations of diffusion-weighted magnetic resonance imaging in kidney, prostate, and bladder cancer including pelvic lymph node staging: a critical analysis of the literature. Eur Urol 2012;61:326-40.

[22] Park JW, Jo MK, Lee HM. Significance of 18F-fluorodeoxyglucose positron-emission tomography/computed tomography for the postoperative surveillance of advanced renal cell carcinoma. BJU Int 2009;103:615-9.

[23] Lim DJ, Carter MF. Computerized tomography in the preoperative staging for pulmonary metastases in patients with renal cell carcinoma. J Urol 1993;150:1112-4.

[24] Koga S, Tsuda S, Nishikido M, et al. The diagnostic value of bone scan in patients with renal cell carcinoma. J Urol 2001;166:2126-8.

[25] Warren KS, McFarlane J. The Bosniak classification of renal cystic masses. BJU Int 2005;95:939-42.

[26] Smith AD, Remer EM, Cox KL, et al. Bosniak category IIF and III cystic renal lesions: outcomes and associations. Radiology 2012;262: 152-60.

[27] Schmidbauer J, Remzi M, Memarsadeghi M, et al. Diagnostic accuracy of computed tomography-guided percutaneous biopsy of renal masses. Eur Urol 2008;53:1003-12.

[28] Leveridge MJ, Finelli A, Kachura JR, et al. Outcomes of small renal mass needle core biopsy, nondiagnostic percutaneous biopsy, and the role of repeat biopsy. Eur Urol 2011;60:578-84.

[29] Abel EJ, Culp SH, Matin SF, et al. Percutaneous biopsy of primary tumor in metastatic renal cell carcinoma to predict high risk pathological features: comparison with nephrectomy assessment. J Urol 2010;184:1877-81.

[30] Volpe A, Mattar K, Finelli A, et al. Contemporary results of percutaneous biopsy of 100 small renal masses: a single center experience. J Urol 2008;180:2333-7.

[31] Breda A, Treat EG, Haft-Candell L, et al. Comparison of accuracy of 14-, 18- and 20-G needles in ex-vivo renal mass biopsy: a prospective, blinded study. BJU Int 2010;105:940-5.

[32] Neuzillet Y, Lechevallier E, Andre M, Daniel L, Coulange C. Accuracy and clinical role of fine needle percutaneous biopsy with computerized tomography guidance of small (less than $4.0 \mathrm{~cm}$ ) renal masses. J Urol 2004;171:1802-5.

[33] Wunderlich H, Hindermann W, Al Mustafa AM, Reichelt O, Junker K, Schubert J. The accuracy of 250 fine needle biopsies of renal tumors. J Urol 2005;174:44-6.

[34] Volpe A, Finelli A, Gill IS, et al. Rationale for percutaneous biopsy and histologic characterisation of renal tumours. Eur Urol 2012; 62:491-504.

[35] Srigley JR, Delahunt B, Eble JN, et al. The International Society of Urological Pathology (ISUP) Vancouver classification of renal neoplasia. Am J Surg Pathol 2013;37:1469-89.

[36] Wahlgren T, Harmenberg U, Sandstrom P, et al. Treatment and overall survival in renal cell carcinoma: a Swedish populationbased study (2000-2008). Br J Cancer 2013;108:1541-9.

[37] Kim SP, Alt AL, Weight CJ, et al. Independent validation of the 2010 American Joint Committee on Cancer TNM classification for renal cell carcinoma: results from a large, single institution cohort. J Urol 2011;185:2035-9.

[38] Waalkes S, Becker F, Schrader AJ, et al. Is there a need to further subclassify pT2 renal cell cancers as implemented by the revised 7th TNM version? Eur Urol 2011;59:258-63.
[39] Ficarra V, Novara G, Secco S, et al. Preoperative aspects and dimensions used for an anatomical (PADUA) classification of renal tumours in patients who are candidates for nephron-sparing surgery. Eur Urol 2009;56:786-93.

[40] Kutikov A, Uzzo RG. The R.E.N.A.L. nephrometry score: a comprehensive standardized system for quantitating renal tumor size, location and depth. J Urol 2009;182:844-53.

[41] Simmons MN, Ching CB, Samplaski MK, Park CH, Gill IS. Kidney tumor location measurement using the $\mathrm{C}$ index method. J Urol 2010;183:1708-13.

[42] Sun M, Lughezzani G, Jeldres C, et al. A proposal for reclassification of the Fuhrman grading system in patients with clear cell renal cell carcinoma. Eur Urol 2009;56:775-81.

[43] Patard JJ, Leray E, Rioux-Leclercq N, et al. Prognostic value of histologic subtypes in renal cell carcinoma: a multicenter experience. J Clin Oncol 2005;23:2763-71.

[44] Frank I, Blute ML, Cheville JC, Lohse CM, Weaver AL, Zincke H. An outcome prediction model for patients with clear cell renal cell carcinoma treated with radical nephrectomy based on tumor stage, size, grade and necrosis: the SSIGN score. J Urol 2002;168:2395-400.

[45] Leibovich BC, Blute ML, Cheville JC, et al. Prediction of progression after radical nephrectomy for patients with clear cell renal cell carcinoma: a stratification tool for prospective clinical trials. Cancer 2003;97:1663-71.

[46] Patard JJ, Kim HL, Lam JS, et al. Use of the University of California Los Angeles integrated staging system to predict survival in renal cell carcinoma: an international multicenter study. J Clin Oncol 2004; 22:3316-22.

[47] Karakiewicz PI, Suardi N, Capitanio U, et al. A preoperative prognostic model for patients treated with nephrectomy for renal cell carcinoma. Eur Urol 2009;55:287-95.

[48] Motzer RJ, Bacik J, Schwartz LH, et al. Prognostic factors for survival in previously treated patients with metastatic renal cell carcinoma. J Clin Oncol 2004;22:454-63.

[49] Heng DY, Xie W, Regan MM, et al. External validation and comparison with other models of the International Metastatic Renal-Cell Carcinoma Database Consortium prognostic model: a populationbased study. Lancet Oncol 2013;14:141-8.

[50] MacLennan S, Imamura M, Lapitan MC, et al. Systematic review of oncological outcomes following surgical management of localised renal cancer. Eur Urol 2012;61:972-93.

[51] MacLennan S, Imamura M, Lapitan MC, et al. Systematic review of perioperative and quality-of-life outcomes following surgical management of localised renal cancer. Eur Urol 2012;62:1097-117.

[52] Van Poppel H, Da Pozzo L, Albrecht W, et al. A prospective, randomised EORTC intergroup phase 3 study comparing the oncologic outcome of elective nephron-sparing surgery and radical nephrectomy for low-stage renal cell carcinoma. Eur Urol 2011;59:543-52.

[53] Capitanio U, Terrone C, Antonelli A, et al. Nephron-sparing techniques independently decrease the risk of cardiovascular events relative to radical nephrectomy in patients with a T1a-T1b renal mass and normal preoperative renal function. Eur Urol 2015;67: 683-9.

[54] Desai MM, Strzempkowski B, Matin SF, et al. Prospective randomized comparison of transperitoneal versus retroperitoneal laparoscopic radical nephrectomy. J Urol 2005;173:38-41.

[55] Marszalek M, Meixl H, Polajnar M, Rauchenwald M, Jeschke K, Madersbacher S. Laparoscopic and open partial nephrectomy: a matched-pair comparison of 200 patients. Eur Urol 2009;55:1171-8.

[56] Gill IS, Kavoussi LR, Lane BR, et al. Comparison of 1,800 laparoscopic and open partial nephrectomies for single renal tumors. J Urol 2007; 178:41-6.

[57] Lane BR, Gill IS. 7-year oncological outcomes after laparoscopic and open partial nephrectomy. J Urol 2010;183:473-9. 
[58] Minervini A, Serni S, Tuccio A, et al. Simple enucleation versus radical nephrectomy in the treatment of pT1a and pT1b renal cell carcinoma. Ann Surg Oncol 2012;19:694-700.

[59] Masson-Lecomte A, Bensalah K, Seringe E, et al. A prospective comparison of surgical and pathological outcomes obtained after robot-assisted or pure laparoscopic partial nephrectomy in moderate to complex renal tumours: results from a French multicentre collaborative study. BJU Int 2013;111:256-63.

[60] Aboumarzouk OM, Stein RJ, Eyraud R, et al. Robotic versus laparoscopic partial nephrectomy: a systematic review and metaanalysis. Eur Urol 2012;62:1023-33.

[61] Kirkali Z, Van Poppel H. A critical analysis of surgery for kidney cancer with vena cava invasion. Eur Urol 2007;52:658-62.

[62] May M, Brookman-Amissah S, Pflanz S, Roigas J, Hoschke B, Kendel F. Pre-operative renal arterial embolisation does not provide survival benefit in patients with radical nephrectomy for renal cell carcinoma. Br J Radiol 2009;82:724-31.

[63] Jewett MA, Mattar K, Basiuk J, et al. Active surveillance of small renal masses: progression patterns of early stage kidney cancer. Eur Urol 2011;60:39-44.

[64] Whitson JM, Harris CR, Meng MV. Population-based comparative effectiveness of nephron-sparing surgery vs ablation for small renal masses. BJU Int 2012;110:1438-43.

[65] Massari F, Bria E, Maines F, et al. Adjuvant treatment for resected renal cell carcinoma: are all strategies equally negative? Potential implications for trial design with targeted agents. Clin Genitourin Cancer 2013;11:471-6.

[66] Flanigan RC, Mickisch G, Sylvester R, Tangen C, Van Poppel H, Crawford ED. Cytoreductive nephrectomy in patients with metastatic renal cancer: a combined analysis. J Urol 2004;171:1071-6.

[67] Heng DY, Wells JC, Rini BI, et al. Cytoreductive nephrectomy in patients with synchronous metastases from renal cell carcinoma: results from the International Metastatic Renal Cell Carcinoma Database Consortium. Eur Urol 2014;66:704-10.

[68] Dabestani S, Marconi L, Hofmann F, et al. Local treatments for metastases of renal cell carcinoma: a systematic review. Lancet Oncol 2014;15:e549-61.

[69] Patard JJ, Rioux-Leclercq N, Fergelot P. Understanding the importance of smart drugs in renal cell carcinoma. Eur Urol 2006;49: 633-43.

[70] Motzer RJ, Mazumdar M, Bacik J, Berg W, Amsterdam A, Ferrara J. Survival and prognostic stratification of 670 patients with advanced renal cell carcinoma. J Clin Oncol 1999;17:2530-40.

[71] Motzer RJ, Hutson TE, Tomczak P, et al. Sunitinib versus interferon alfa in metastatic renal-cell carcinoma. N Engl J Med 2007;356:115-24.

[72] Escudier B, Bellmunt J, Negrier S, et al. Phase III trial of bevacizumab plus interferon alfa-2a in patients with metastatic renal cell carcinoma (AVOREN): final analysis of overall survival. J Clin Oncol 2010;28:2144-50.

[73] Motzer RJ, Hutson TE, Cella D, et al. Pazopanib versus sunitinib in metastatic renal-cell carcinoma. N Engl J Med 2013;369:722-31.

[74] Hudes G, Carducci M, Tomczak P, et al. Temsirolimus, interferon alfa, or both for advanced renal-cell carcinoma. N Engl J Med 2007; 356:2271-81

[75] Tannir NM, Jonasch E, Altinmakas E, et al. Everolimus versus sunitinib prospective evaluation in metastatic non-clear cell renal cell carcinoma (the ESPN trial): a multicenter randomized phase 2 trial. J Clin Oncol 2014;32(5 Suppl):4505.

[76] Sun M, Shariat SF, Cheng C, et al. Prognostic factors and predictive models in renal cell carcinoma: a contemporary review. Eur Urol 2011;60:644-61.

[77] Zisman A, Pantuck AJ, Dorey F, et al. Improved prognostication of renal cell carcinoma using an integrated staging system. J Clin Oncol 2001;19:1649-57.

\title{
http://esusalzburg.uroweb.org
}

\section{ESU - Weill Cornell Masterclass in General urology}

\author{
5-11 July 2015, Salzburg, Austria
}

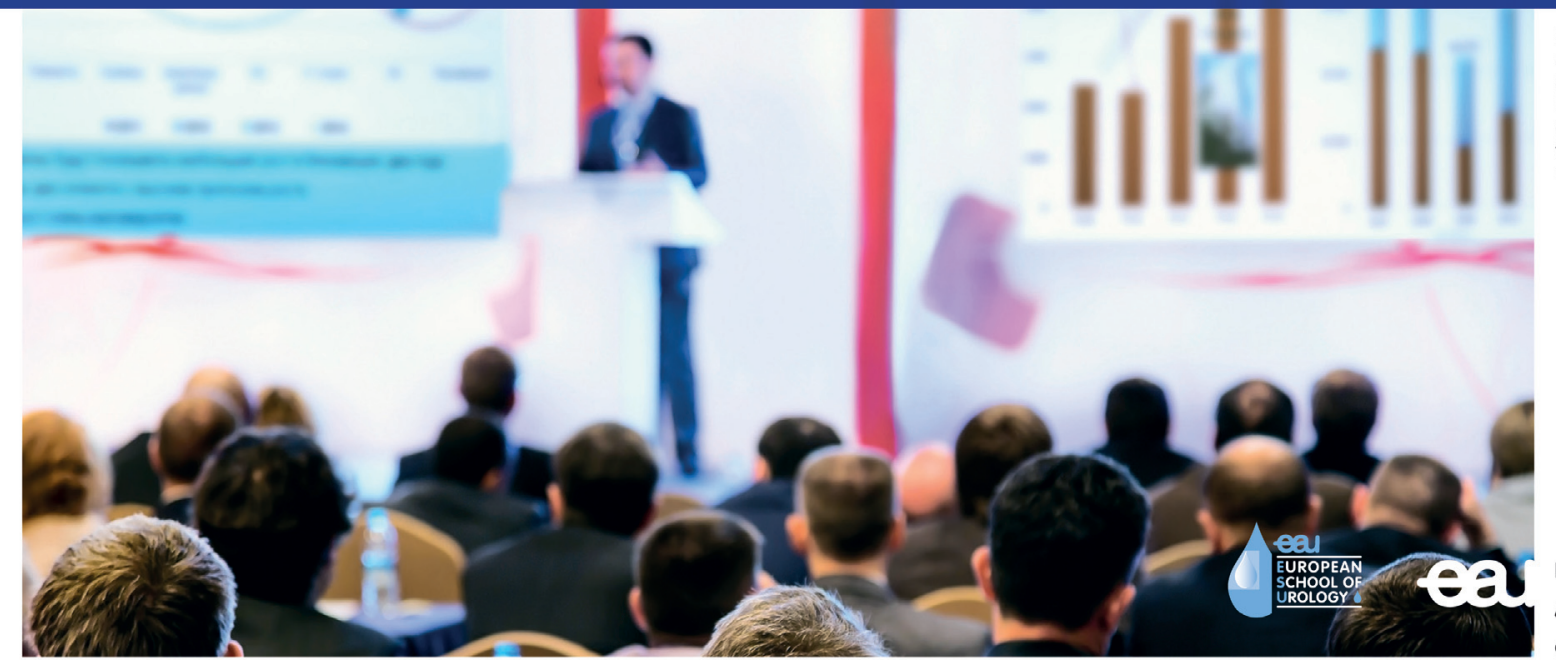

EAU meetings and courses by the EBU in com the in compliance with regulations 